\title{
Bahriye Sağ Kolağası Hüseyin Efendi; Hamidiye Etfal Hastanesi’nde illk Pediatrik Fizyoterapi ve Ortez-Protez Uygulamaları*
}

\author{
Navy Senior Captain Huseyin Efendi; The First Pediatric Rehabilitation and Orthosis-Prothesis Practices in \\ Hamidiye Etfal Hospital \\ Safa Heybet
}

'Öğr. Gör. Biruni Üniversitesi Sağlık Hizmetleri Meslek Yüksekokulu, https://orcid.org/0000-0002-9263-1613

Öz

Amaç: Osmanlı Devletinde modern anlamda ilk pediatrik rehabilitasyon ve ortez-protez hizmetlerini başlatmış olan Bahriye Sağ Kolağası Hüseyin Efendi'yi araştırmak ve çalışmalarını sunmaktır.

Yöntem: Çalışma için Türkiye Cumhuriyeti Cumhurbaşkanlığı Devlet Arşivleri Kataloglarında tarama yapılmış, Hamidiye Etfal Hastanesinin hastane kayıtları incelenerek yapılan işler kayıt altına alınmıştır.

Bulgular: Bahriye Sağkolağası Hüseyin Efendi miladi 1893 yılında Fransa'da aldığı ortez protez ve ameliyat cihazları eğitiminin ardından Hamidiye Etfal Hastanesinde pediatrik fizyoterapi ve rehabilitasyon biriminde görev almış, buradaki görevini 1908 yılına kadar sürdürmüş, hamidiye etfal hastanesinde ve tersane-i amirede alat-ı nazike imalathanesinde ortez ve pretez uygulamalarına devam etmiştir.

Sonuç: Bahriye Sağ Kolağası Hüseyin Efendinin ve çağdaşı hekimlerin 1903-1908 yılları arasında gerçekleştirdiği uygulamalar, Türkiye'de günümüzdeki pediatrik fizyoterapinin başlangıç noktası olmuş, Hüseyin Efendinin yetiştirdiği öğrenciler ülkemizde ortezprotez mesleğinin başlamasını sağlamıştır.

Anahtar Sözcükler: Rehabilitasyon, Ortez, Protez

\section{ABSTRACT}

Aim: The aim of this research, research and present Navy Senior Captain Huseyin Efendi, who started the pediatric rehabilitation services in the modern sense in Ottoman Empire

Method: The study was performed in the catalogs of the Turkish Republic Presidency State Archives and the hospital records of the Hamidiye Etfal Hospital were examined and the works were recorded.

Results: Navy Senior Captain Hüseyin Efendi, after the orthosis prosthesis and surgical devices training he received in France in 1893, he worked in the pediatric physiotherapy and rehabilitation unit at Hamidiye Etfal Hospital, where he worked until 1908, in the hamidiye etfal hospital and the Golden Horn Shipyard (Tersane-i Amire) Fine Tools (alat-ı nazike) manufacturing facility for prosthesis applications

Conclusion: The practices which performed by Navy Senior Captain Hüseyin Efendi in 1903-1908, today became the starting point for the pediatric physiotherapy in Turkey, which educates students in our country has led to the start of the orthotic prosthetic profession.

Keywords: Rehabilitation, Orthosis, Prothesis

*Lokman Hekim Dergisi, 2020; 10 (1): 77-83

DOI: $10.31020 /$ mutftd.628772

e-ISSN: $1309-8004$

Geliş Tarihi - Received: 03 Ekim 2019; Kabul Tarihi - Accepted: 08 Aralık 2019

Iletişim - Correspondence Author: Safa Heybet <sheybet@biruni.edu.tr> 


\section{GíRiş}

Pediatrik Fizyoterapi ve Rehabilitasyon, çocukların doğuştan veya sonradan sahip olduğu bedensel engel durumlarını rehabilite etmeyi amaçlayan rehabilitasyonun alt dallarından biridir. Tarihsel açıdan değerlendirildiğinde, rehabilitasyon ekibi, çocukların bakımı olan her alanda ailelere ve bakıcılara destek olmuş ve önerilerde bulunmuş, o zamandan beri tam yapılandırımış tedavi programlarını ve egzersiz yaklaşımlarını uygulamışlardır. ${ }^{1}$ Dünyada fizyoterapi ve rehabilitasyon uygulamaları XVIII. yüzyılda ortopedi biliminin gelişmesi ve egzersizin insan vücuduna faydasının kanıtlanması sonucu İsveç, Norveç, Hollanda ve Almanya da kurulan mesleki cemiyetler ile başlamıştır. ${ }^{2}$ IXX. yüzyılda poliomyelit tedavisinin geliştirilmesi sonrası hastalığın sekellerinin iyileştirilmesi amacıyla yapılan uygulamalar pediatrik rehabilitasyonun başlangıcını oluşturmuştur. Fizyoterapi Rehabilitasyon hizmetleri ülkemizde ilk defa Prof. Dr. İhsan Doğramacı tarafından Hacettepe üniversitesinde açılan Fizyoterapi ve Rehabilitasyon okulu ile başlamış olsa dahi mesleğin tarihsel gelişimi ülkemizde daha eski bireysel çabalara sahiptir. ${ }^{3}$ Gülhane Askeri Tıp Akademisi, ülkemizde fizyoterapi ve rehabilitasyon uygulamalarının başladığı merkezlerden biridir. 1898 yılında zamanın Osmanlı Hükumeti tıp eğitiminde köklü bir ıslahat yapmak üzere Almanya'dan bir üniversite hocasının getirilmesine karar vermiştir; Topkapı Sarayı duvarları içinde Gülhane adı verilen eski Askeri Rüştiye binası tahsis edilmiş ve 30 Aralık 1898 'de açılmıştır. Gülhane'nin masaj kısmının yönetimi aynı yıllarda Almanya'dan getirilen Dr. Hoffmann'a ve yardımcısı Yzb. Şemsettin Ateş'e verilmiştir. Dr. Hoffmann haftada bir saat masaj kursları vermeye başlamış ve bir mekanoterapi salonu kurmuştur. 1904 yılında Tbp. Bnb. Şemsettin Ateş hocası emekliye ayrılıp yurduna dönünce "Tedavi-i Mihaniki ve Masaj" hocalığına atanmıştır. ${ }^{4}$ Bu dönemde ülkemizde fizyoterapi hizmetlerinin yaygınlaşması için çaba gösteren bir diğer hekim İzzet Emin'dir. Kendisi Mekteb-i Tıbbiye-yi Şahane'de aldığı eğitimin ardından Fransa'da Mathieu kliniğinde eğitim almış, İstanbul'a dönüşünün ardından sarayda görevlendirilmiş ve paşa unvanı almıştır. Kendisi daha sonra Bezmialem Vakıf Gureba Hastanesine başhekim olarak atanmış ve bu hastaneye ilk fizyoterapi cihazlarının getirilmesini sağlamıştır. ${ }^{4}$

Tüm dünyada olduğu gibi ülkemizde de rehabilitasyon hizmetleri geçtiğimiz yüzyılın başında kurumsallaşmış ve sistematik bir temel üzerine kurulmuştur. Bu kurumsallaşmanın oluşmasında bireysel çabaların da etkisi büyüktür. Sistematik temelin kurulmasında etkili şahsiyetlerden biri de Bahriye Çarkçı Sağ Kolağası Hüseyin Efendi'dir. Hamidiye Etfal Hastanesinde 1902 yılında kurulan "fiziko tedavi pavyonuna" 1903 yllında padişah iradesi ile tayin olunan Hüseyin Efendi, 31 Mart vakası olarak bilinen, Sultan II. Abdulhamid'in hal edilmesi zamanına kadar burada çalışmış, bu dönemden sonra çalışmalarını Tersane-i amire ve Kadıköy'deki evinde devam ettirmiştir.

Bu çalışmanın amacı Bahriye Çarkçı Sağ Kol Ağası Hüseyin Efendinin Hamidiye Etfal Hastanesine gelişi, hastanedeki çalışmaları ve hastane sonrası dönemine ışık tutmaktır.

\section{YÖNTEM}

Çalışma kapsamında Türkiye Cumhuriyeti Cumhurbaşkanlığı Devlet Arşivleri Kataloglarında tarama yapılmış, 100.yılında Hamidiye Etfal Hastanesi çalışmaları, hastanenin 1902-1908 yılları arasındaki hastanenin istatistik yıllıkları ve Ortopedi hekimi Hayri Tanaçan'ın anıları derlenmiş, bunların içinden Hüseyin Efendinin çalışma hayatı takip edilmiştir. Hüseyin efendinin Paris'te pediatrik rehabilitasyon ve ortez-protez alanında mesleği öğrendiği ve çalıştığı merkez, Royal College of Surgeons of England arşivinden teyit edilmiştir.

\section{BULGULAR}

Bahriye Sağ Kol Ağası Hüseyin Efendinin çocuk fizyoterapisine ve ortez protez sektörüne attı̆̆ı ilk adım, Masarifat-ı Umumiye-i Askeriye Nazırı Sadettin Paşanın ampute bacağı için yurtdışına sipariş edilen protezdir. $^{3}$ Sadettin paşanın protezi üç defa değiştirilmiş, üçüncü değişimde proteze 300 altın istenmesi 
üzerine Sultan II. Abdulhamid, bahriye subaylarının bu iş için yurtdışında eğitilmesi emrini vermiştir. Emir üzerine Bahriyeden iki subay, Tophane'den iki subay olmak üzere dört subay eğitim için görevlendirilmiştir. ${ }^{4}$

Hüseyin Efendi bahriyeden seçilen subaylardan biri olarak Paris'e gönderilmiştir. Bu konuyla ilgili olarak bahriye arşivinde şu ibare yer almaktadır: "Sun-i aza imalini tahsil için rüfekayı dairesiyle beraber Paris'te Mösyö Mathieu'nün fabrikasına gönderilmiş olan Zabıtan-ı Bahriyeden Kolağası Hüseyin Efendi”... (28 Zilkade 1310 Hicri 13 Haziran 1893 Miladi) Hüseyin efendinin bu dönemde eğitime gittiği L. Mathieu imalathanesi araştırıldığında bu kişinin Lucien Mathieu olduğu, 1864 yılında yayınladığı kataloğunun önsözünde 15 yıldır bu alanda çalıştı̆̆ı, ameliyathane araç gereçlerini icat ettiğini ve mevcut cihazları ürettiğini ifade etmiştir. Kullandığı yüksek kaliteli hammaddeler ile hekimlerin ihtiyaç duyabileceği özelleşmiş her türlü ameliyathane ekipmanını üretebileceğini ifade eden Mathieu, bu alanda ürettiği ürünler ile 1861 yılında universal fuarda ilk madalyasını almıştır. Londra 1862 Evrensel Sergisinde jüri, kendisine, büyük ustalık, buluş, enstrümanların mükemmelliği ve iş̧̧iliğin parlaklığı dolayısıyla madalya vermiştir. 1862 yılının sonunda Tıp Fakültesi, ortopedik cihazların ve özellikle de brakiyal protezin mükemmelliği nedeniyle kendisine Barbier Ödülü'nü takdim etmiştir. Son olarak, 15 Aralık 1863'teki toplantıda, İmparatorluk Tıp Akademisi, bir ödül olarak, Argenteuil'den (Argenteuil, Fransa'nın île-de-France bölgesine bağlı Val-d'Oise departmanında bulunan bir şehir ve belediyedir.) alınan paranın bir kısmını idrar yolu hastalıkları için icat ettiği ürünler için vermiştir.

Bahriye Kolağası Hüseyin Efendinin eğitim gördüğü, o dönemde ameliyathane cihazları ve tıbbi aletler üreten L. Mathieu şirketinin ürün kataloğunun kapağı aşağıda yer almaktadır. ${ }^{5}$ (Şekil 1)

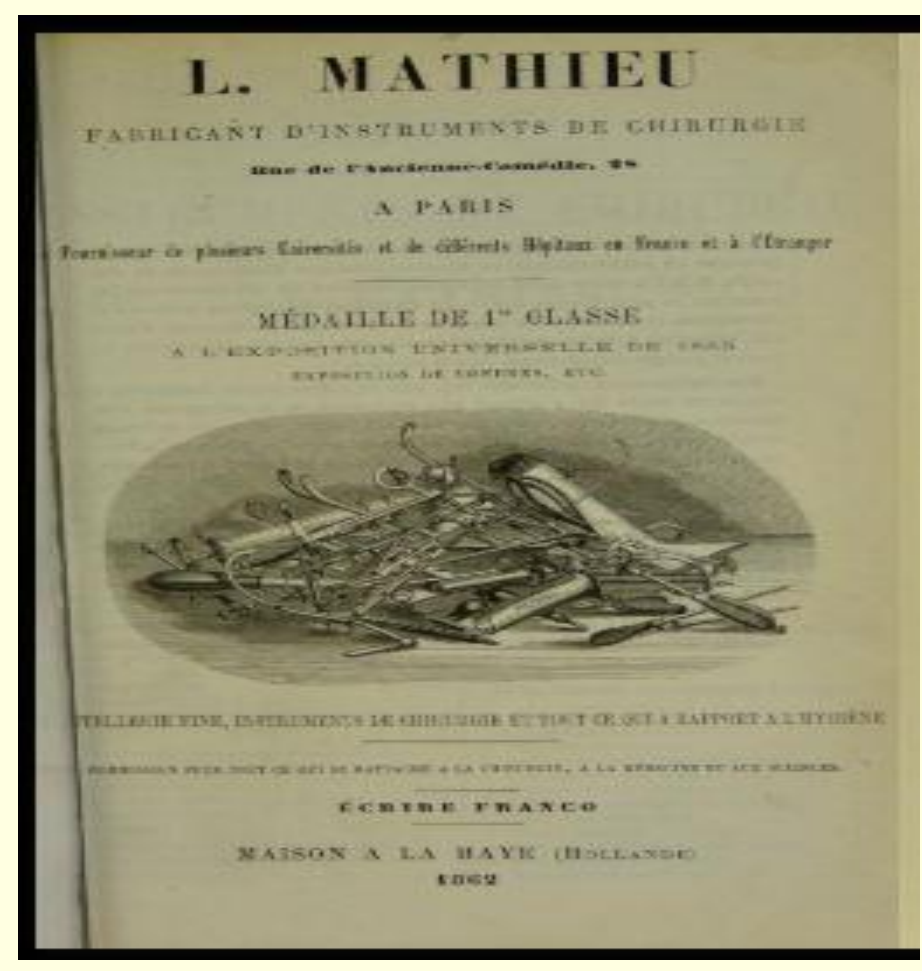

Şekil 1. L. Mathieu şirketinin 1862 tarihli kataloğunun kapak sayfası

Hüseyin Efendinin Paris'te bu klinikte bir yıl kaldığı ve "Kendisinin kifayet ve ehliyeti Karin-i tasdik-i ali olduğu takdirde o vakit İngiltere veya Almanya fabrikalarından birine gönderilmek üzere mumaileyhin şimdilik Dersaadet'e celbi muktezayı irade-i Cenab- I Hilafet penahi'ye den bulunmakla emrü ferman menlehül emirdir. (Kendisinin yeterlilik ve ustalığı tasdik edildiği takdirde İngiltere ve Almanya fabrikalarından birine gönderilmek üzere adı geçen kişinin şimdilik İstanbul'a gelmesi gerektiği padişah 
iradesiyle buyurulmakla, emir ve ferman emir sahibi kimsenindir. $)^{6 \prime \prime}$ fermanıyla 1893 yılında geri çağırıldığı anlaşılmıştır. ${ }^{4}$

Hüseyin Efendi Paris'ten döndükten sonra ilk suni aza atölyesini Yıldız Sarayı bünyesinde kurmuştur. Daha sonra Tersane-i Amire'de Alat-ı Nazike İmalathanesi adıyla ikinci atölyesini açmıştır. ${ }^{4}$

Sultan II. Abdulhamid'in kızı Hatice Sultan'ın 14 Şubat 1898 tarihinde Difteri hastalığı nedeniyle ölümünün ardından İstanbul'daki çocukların sağlık hizmetine erişiminin kolaylaştırılması amacıyla Hamidiye Etfal Hastanesi hizmete girmiştir. Hastanenin açılmasından bir süre sonra burada çocukların fizyoterapi ve rehabilitasyon hizmetlerinin de verilmesi gerektiği düşünülmüştür. Bu nedenle hastane bünyesinde 1902 yılında karakol ile büyük pavyonun ortasında, "etfalin jimnastik ile takviye-i vücudu ameliyesine mahsus olarak"” (Çocukların Jimnastik ile vücut takviyesi uygulamasına mahsus olarak) küçük bir pavyon yapılmış ve fizik tedavi için gereken en son teknolojide araç gereç ile donatılmıştır. ${ }^{8}$ Dört numara ile gösterilen fizyoterapi pavyonunun (bölümünün) istatistik yıllığındaki çizimi aşă̆ıda yer almaktadır (Şekil 2).

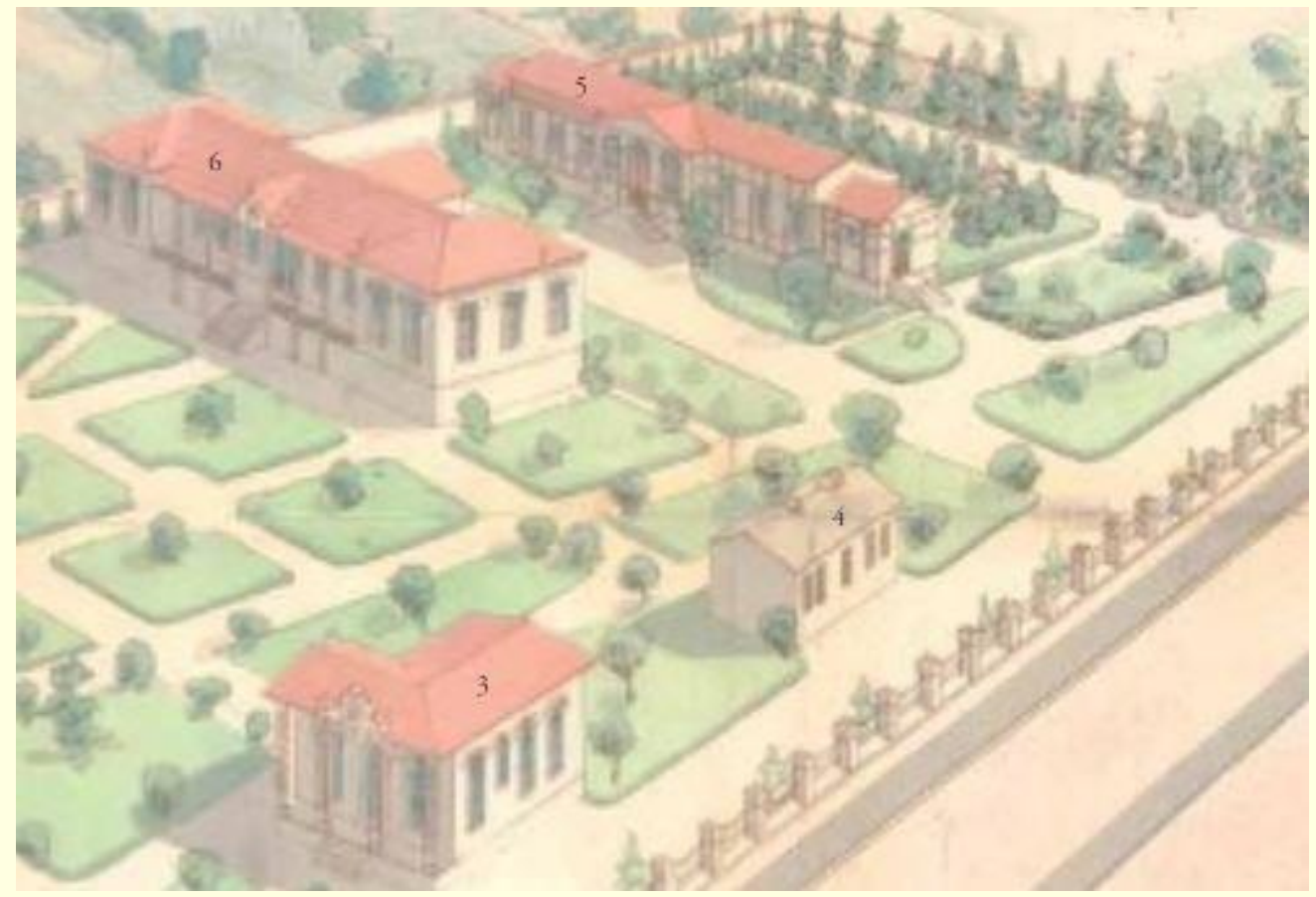

Şekil 2: Hamidiye Etfal Hastanesi Fizyoterapi Yerleşimi

Hüseyin Efendi burada hem çocukların egzersizleri ile ilgilenmiş, hem de çocukların ihtiyaç duydukları ortez ve protezleri buradaki ve Tersane-i Amire'deki atölyesinde imal etmiştir. Hüseyin efendinin istatistik yıllı̆ıında, personel kaydında ismi ve görevi aleti cerrahiye ve sun-i ayak imaline memur Bahriye Çarkçı Kolağalarından Hüseyin Efendi olarak geçmektedir. Kendisi hekim veya sağlık personeli olmamasına rağmen Fransa'da gördüğü eğitim neticesinde bu göreve getirilmiştir. Hüseyin efendinin Hamidiye Etfal Hastanesinin istatistik yıllıklarında hangi çocuklarla ne amaçla ilgilendiğine dair bir bilgiye rastlanmamıştır. Hüseyin efendinin Osmanlı arşivlerinin yıldız sarayı kayıtlarında fakir çocukların ayaklarının tedavisi hakkında ve haftanın belirli günleri tersane-i amireye gitmek amacıyla izin istediği iki dilekçe bulunmaktadır. Hüseyin efendinin Hamidiye etfal hastanesindeki faaliyetlerinin birinde İzmit Sancağı Bağçecik nahiyesinden Kavas Mehmet Ağa'nın kızı Fatma ayağından ameliyat edilmiş ve diz-kapağından aşağı protezi Tersane-i Âmire'de yaptırılmıştır. ${ }^{9}$ Bu ameliyat ve yapılacak protezin ücretinin hazine-i hassadan karşılanması amacıyla hazırlanan dilekçe Resim 3 ve 4'te gösterilmiştir. (Şekil 3 ve 4). 


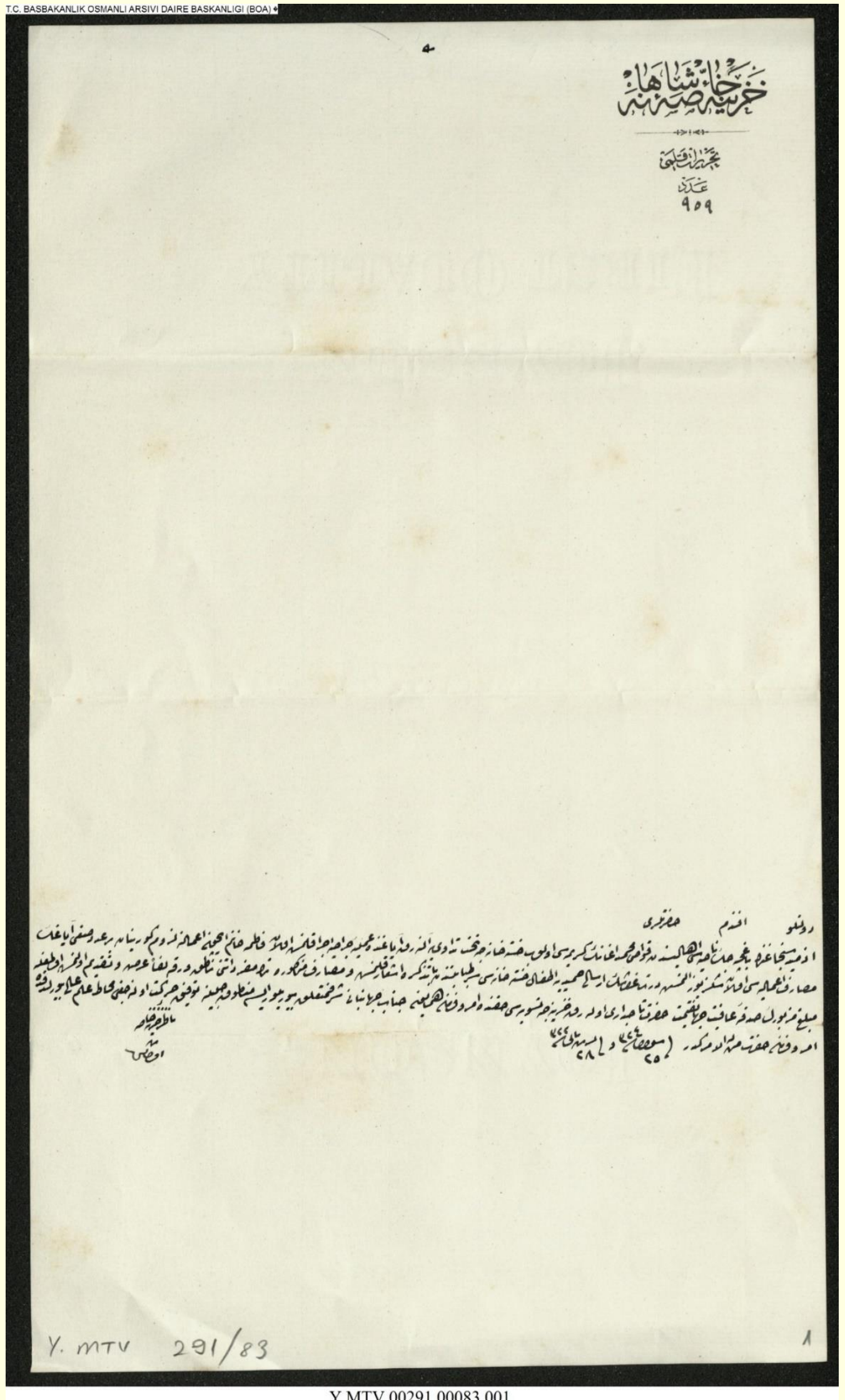

Y.MTV.00291.00083.001

Şekil 3. Hüseyin Efendi'nin hazırladığı protez malzeme listesi-1 


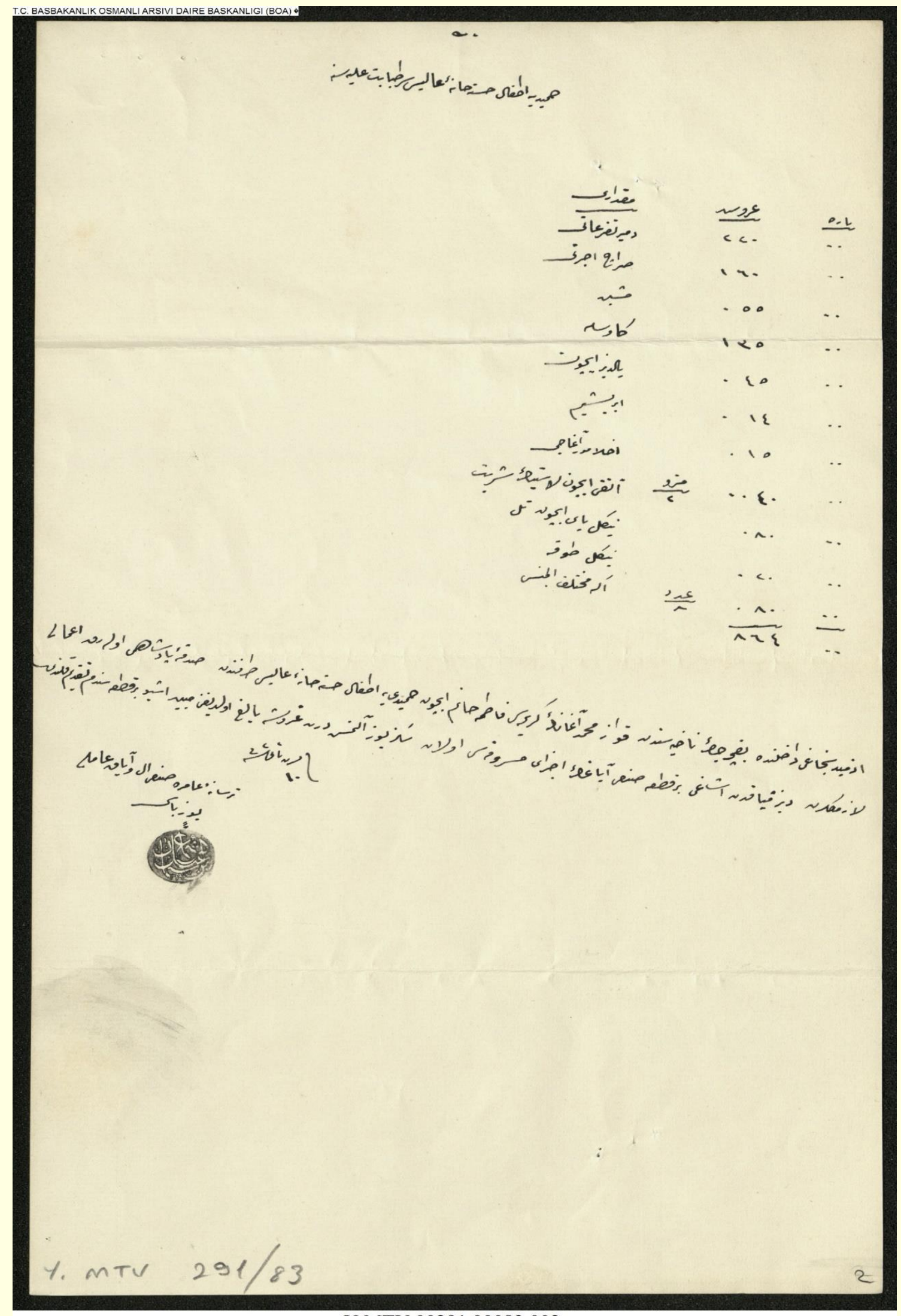

Y.MTV.00291.00083.002

Şekil 4. Hüseyin Efendi'nin hazırladığı protez malzeme listesi-2 
Hüseyin efendi, sadece ortez-protez imalatı yapmamış, aynı zamanda öğrenci de yetiştirmiştir. Yetiştirdiği öğrencilerden Baki Gemici ile 7-8 yıl süresince Tersane-i Amire'de çalışmış. Birçok protez ve ortez modeli üretmişlerdir.

1.Dünya Savaşının başlaması ile birlikte 1914 yılında Alat-ı Nazike İmalathanesi ordunun emrine verilmiş ve Gülhane'ye taşınmıştır. Hüseyin Efendi ve talebesi Baki Gemici üç yıl ordu emrinde çalışıp, yerlerine teknisyenler yetiştirdikten sonra Gülhane'den ayrılmışlardır. Bu atölye Trablusgarb, Balkan ve 1.Dünya Savaşı süresince askerlerin protezlerinin üretildiği tek merkez olarak faaliyet göstermiştir. Atölye, 1924'te ise Ankara'ya taşınmıştır. Atölyenin 1924 yılındaki taşınması ile 1948 yılında Gülhane askeri tıp akademisi bünyesinde kurulan ortez-protez merkezi arasındaki 24 yıl hakkında bilgi ve belge bulunamamıştır.

Gülhane Alat-ı Nazike imalathanesinde üç yıl çalıştıktan sonra Hüseyin efendi bir müddet Bahriye mesleğine geri dönmüş, ancak daha sonra ordudan ayrılarak Kadıköy'de kendi konağında hususi olarak Ortez-protez üretimine devam etmiştir. ${ }^{4}$

\section{SONUÇ}

Hüseyin Efendinin Fransa'da başlayan, Yıldız sarayı ve Tersane-i Amire'de devam eden, Hamidiye Etfal Hastanesinde pediatrik rehabilitasyon uygulamalarını da kapsayan son olarak Gülhane Alat-ı Nazike imalathanesinde sona eren meslek yaşamı, çağdaşları ile birlikte ülkemizde fizyoterapi ve protez-ortez alanında yeni bir sayfa açmıştır. Kendisinin çalışmalarının araştırıması bu iki mesleğin ülkemizdeki kökenlerini anlamamız açısından önem arz etmektedir.

\section{BiLGi}

Çalışma 07-10.03.2019 tarihinde Amasya Üniversitesi'nde düzenlenen Amasya Sağlık Kültür Toplum Sempozyumu'nda sunulmuştur. Araştırmayı destekleyen kuruluş bulunmamaktadır.

\section{KAYNAKLAR}

1. Carter A. Pediatrik Fizyoterapinin Prensipleri, Porter S., Tidy's Physiotherapy, Londra, Butterworth-Heinemann, 2003 pp:183-193.

2. Bakewell S. Illustrations from the Wellcome Institute Library: Medical gymnastics and the Cyriax collection. Medical history 1997;41(04):487-495.

2. Can F. Fizyoterapi ve Rehabilitasyonun Mesleki Gelişim Tarihçesi, İzmir Kâtip Çelebi Üniversitesi Sağlık Bilimleri Fakültesi Dergisi 2016;3:1-6

3. Önal S. Sadettin Paşa'nın Anıları, İstanbul: Remzi Kitabevi, 2003.

4. Arasıl T. Türkiye'de ve Dünyada Fiziksel Tıp ve Rehabilitasyonun Durumu, Türk Fiz Tıp Rehab Derg 2008; 54 Özel Sayı 1: 1-3

4. Tanaçan B. Türk Ortopedisinin Tarihçesi, Acta Orthop Traumatol Turc 1993;27:151-159

5. Catalogue des instruments de chirurgie by L. Mathieu (Firm); Royal College of Surgeons of England, 1862, https://archive.org [internet]

6. Bahriye nezareti "Bölüm mektubi defter" 1893, no. 773, sayfa 5

7. İstatistik “Hamidiye Etfal Hastane-i Âlisi'nin geçen bir sene zarfındaki terakkiyatı”, 1903, 20 sayfa:47

8. Turgut S. Hastane Tarihimizde Bir Kutup Yıldızı: Hamidiye Etfal Hastanesi, Şişli Etfal Eğitim ve Araştırma Hastanesi, s:50-51, 2010.

9. Cumhurbaşkanlığı Osmanlı Arşivleri (1906) BOA. Y. MTV. 291/83, 25 L. 1324 